\title{
Stage 0 Nasal Cavity Cancer AJCC v6, v7, and v8
}

National Cancer Institute

\section{Source}

National Cancer Institute. Stage O Nasal Cavity Cancer A/CC v6, v7, and v8. NCI

Thesaurus. Code C4589.

Stage 0 includes: T is, NO, MO. T is: Carcinoma in situ. NO: No regional lymph node metastasis. M0: No distant metastasis. (AJCC 6th, 7th, and 8th eds.) 